\title{
Skull base approaches in neurosurgery
}

\author{
Martin Scholz' , Richard Parvin*2, Jost Thissen' ${ }^{1}$, Catharina Löhnert ${ }^{1}$, Albrecht Harders ${ }^{3}$ and Klaus Blaeser ${ }^{1}$
}

\begin{abstract}
The skull base surgery is one of the most demanding surgeries. There are different structures that can be injured easily, by operating in the skull base. It is very important for the neurosurgeon to choose the right approach in order to reach the lesion without harming the other intact structures. Due to the pioneering work of Cushing, Hirsch, Yasargil, Krause, Dandy and other dedicated neurosurgeons, it is possible to address the tumor and other lesions in the anterior, the mid-line and the posterior cranial base. With the transsphenoidal, the frontolateral, the pterional and the lateral suboccipital approach nearly every region of the skull base is exposable.

In the current state many different skull base approaches are described for various neurosurgical diseases during the last 20 years. The selection of an approach may differ from country to country, e.g., in the United States orbitozygomaticotomy for special lesions of the anterior skull base or petrosectomy for clivus meningiomas, are found more frequently than in Europe.

The reason for writing the review was the question: Are there keyhole approaches with which someone can deal with a vast variety of lesions in the neurosurgical field?

In my opinion the different surgical approaches mentioned above cover almost 95\% of all skull base tumors and lesions. In the following text these approaches will be described.

These approaches are:

1) pterional approach

2) frontolateral approach

3) transsphenoidal approach

4) suboccipital lateral approach

These approaches can be extended and combined with each other. In the following we want to enhance this philosophy.
\end{abstract}

\section{Ad 1) pterional approach Historical overview}

In the $1970 \mathrm{~s}$ Yasargil [1,2] laid to the foundation of the pterional approach. The pterional approach allows the surgeon to address the circle of Willis and also pathological changes in the cavernous sinus area. In the 1960s Parkinson $[3,4]$ championed a route that exposed the cavernous sinus with less retraction of the brain then earlier approaches. The pterional approach is the standard surgical treatment for aneurysms in the anterior circle of Willis. During the Cushing era the term "nole mi tangere" ("don't touch me") was a rule for neurological surgeons, which considered treating intracranial aneurysms. The forefathers of aneurysm surgery were Norman Dott [5] and Walter Dandy [6]. Dott reported the first surgical

\footnotetext{
* Correspondence: richard.parvin@rub.de

2 Ruhr-University Bochum, Germany

Full list of author information is available at the end of the article
}

treatment of an intracranial aneurysm. His patient suffered from an aneurismal subarachnoid hemorrhage. Dandy [7] was the first to begin clipping aneurysms of the internal carotid artery. Tönnis [8] was one of the first to treat aneurysms in the circle of Willis. While Tönnis' route through the anterior part of the corpus callosum showed successful results, his first try to expose the aneurysm of the anterior communication artery by a subfrontal approach did not succeed.

\section{Surgical technique}

There are many variants for the pterional approach. Mainly it is a trepanation which permits access to the frontal and to the temporal lobe as well as the Sylvian fissure (Figure 1, Figure 2). After a curved skin incision the Galea is retracted. For treatment of the temporal muscle there are different variants which have all there clear indication. Many surgeons cut the muscle directly during skin 


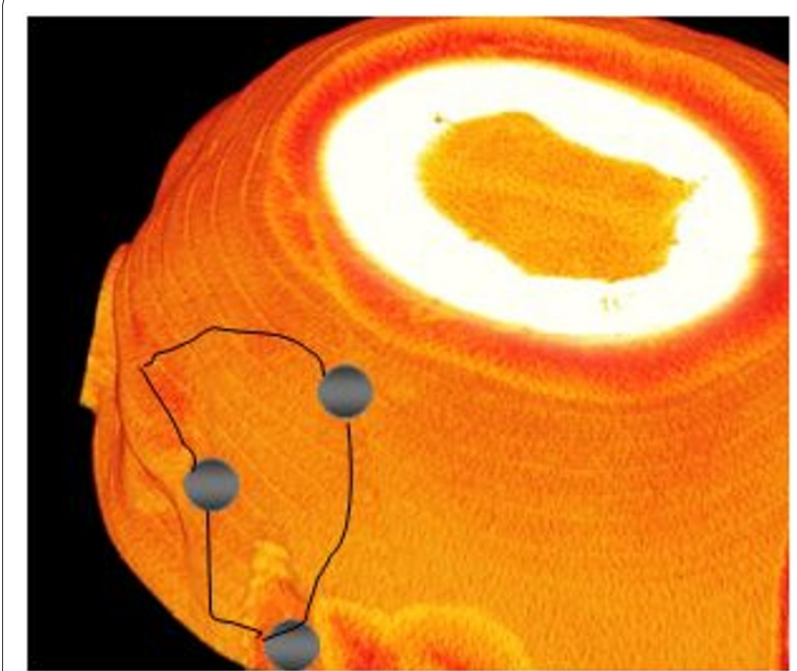

Figure 1 Pterional approach on the left side. Normally three burr holes are used.

incision and separating the combined musculocutaneous flap down until they reach pterion and the frontobasal are above the eye brow. The temporal muscle has to be separated carefully to approach the temporal bone.

Yasargil also described a technique that allows access to the same area: his skin incision is done until the temporal fascia is reached. He then creates a triangular galea flap and seperates the muscle after additional horizontal incision in order to protect the frontal branch of the facial Nerve. In our opinion the rate of nerve injury is minimal also if one is using the first technique. The advantage of the Yasargil Technique can be seen if one wants to combine the pterional approach with the subfrontal approach. The muscle can be retracted much easier downwards

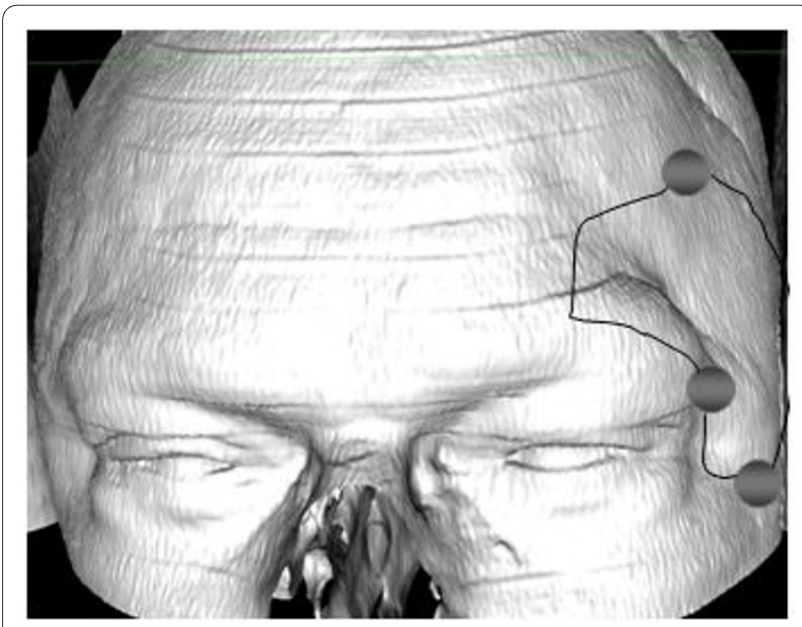

Figure 2 Pterional approach from the frontal view. with this technique. In my opinion the rate of atrophic changes of the temporal muscle postoperatively is a little bit higher. We are using Palacaos to fill the burr holes. Other authors are using selected bone dust.

\section{Case report 1}

A 51-year-old man underwent an operation for a craniopharyngioma, through a pterional approach from the right side six months before. He was presented with a pituitary infarction. He has been treated with Testosterone (Testogel), Desmopressin (Minirin) and Hydrocortisone. He suffered from a progressive visual disturbance (visual acuity r $0.6,10.8$ ) for 8 weeks. A bitemporal hemianopsia was diagnosed.

\section{Outcome}

We diagnosed a recurrence of the craniopharyngioma (Figure 3, Figure 4, Figure 5). Besides the postoperative right-sided temporal disturbance of the visual acuity, there were no other neurological deficits. The patient still has to substitute the endocrine system.

\section{Case report 2}

64-year-old woman presented with unknown symptoms of vertigo and diplopia. Further there were no clinical deficits. The MRI showed a left space-consuming lesion latero para- and retrosellar of approximately $2 \times 2,5 \mathrm{~cm}$ size (Figure 6). We suspected a dorsum sellae meningioma. The intraoperative view demonstrates the exact location of the tumor (Figure 7, Figure 8, Figure 9).

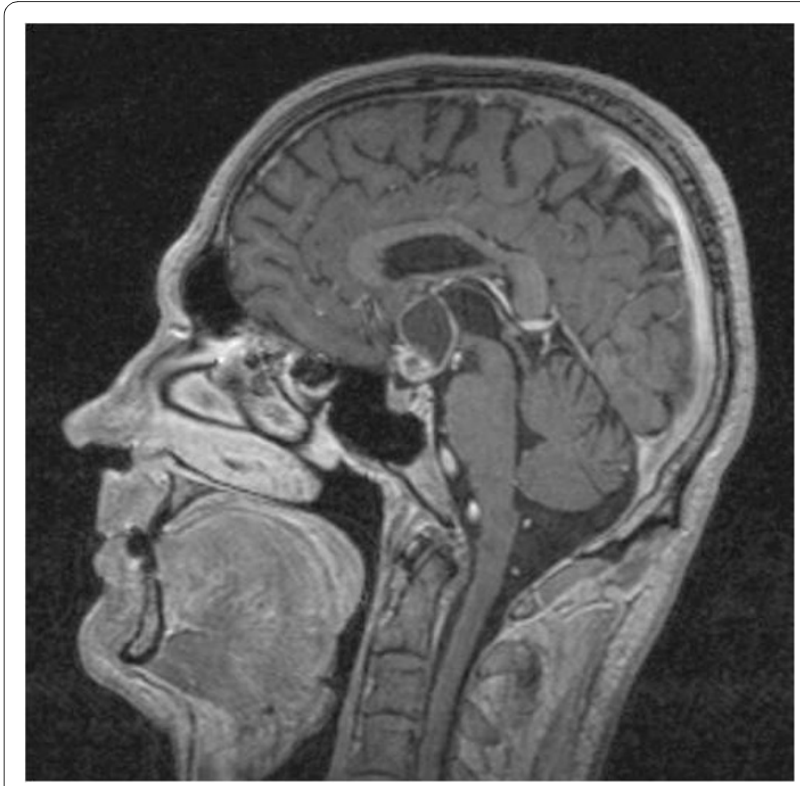

Figure 3 Sagittal brain MRI of a 51 year old male with a recurrence of a craniopharyngioma. The MRI demonstrates the hypertensive solid part and above, it demonstrates the cystic part. 


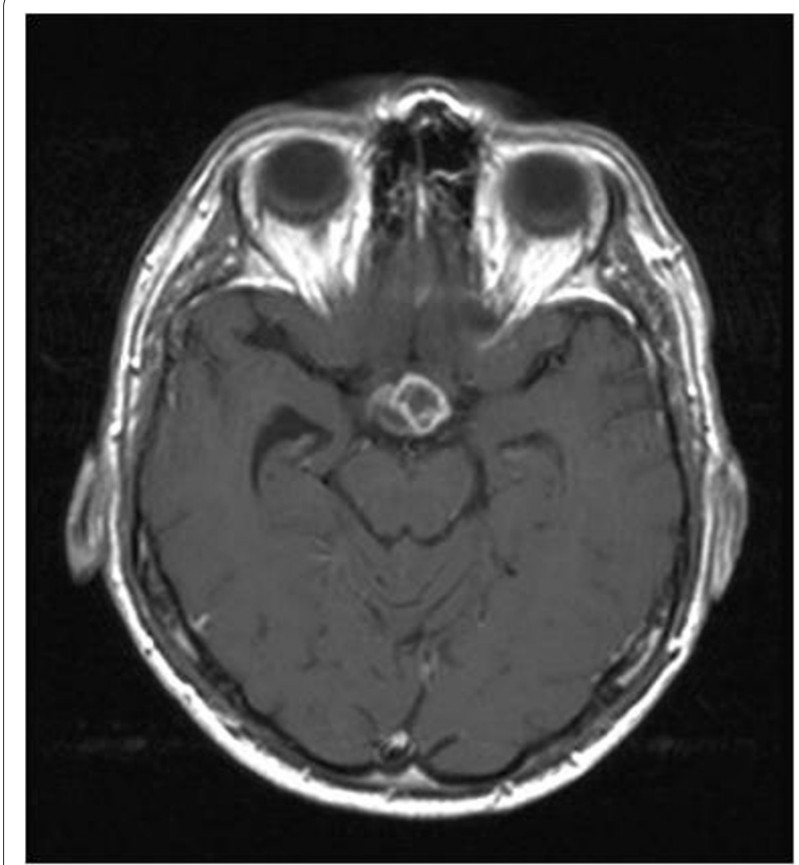

Figure 4 Axial brain MRI of a 51 year old male

\section{Outcome}

There were normal findings post-operatively with occasional diplopia, while the wound was healing per primam. Pathology revealed a meningothelial tumor of WHO grade I.

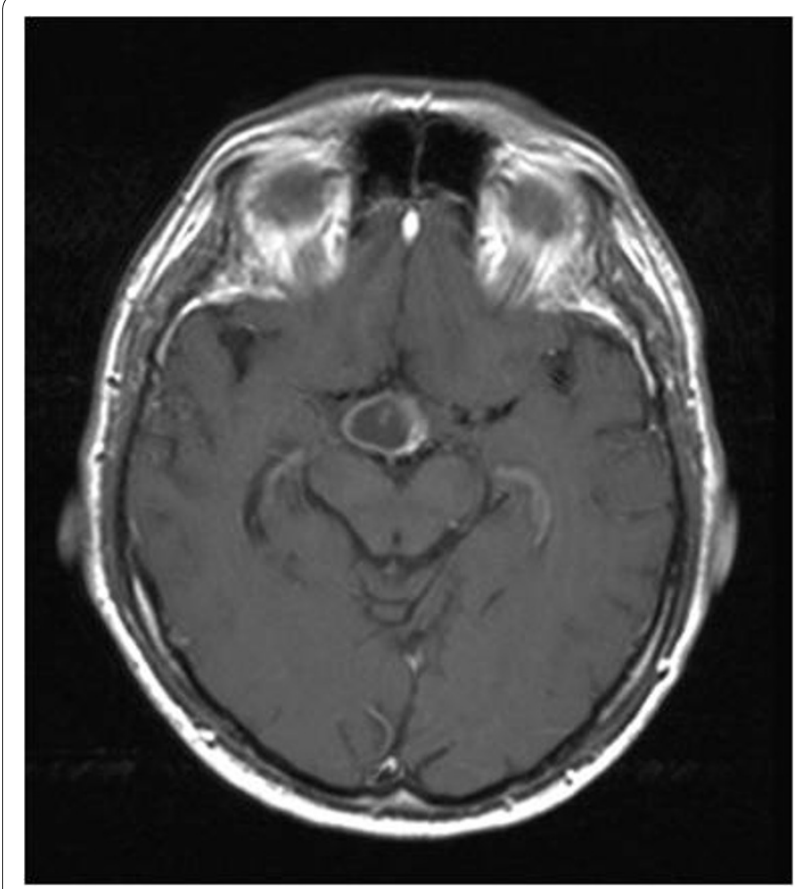

Figure 5 Axial brain MRI of a 51 year old male in a different slice

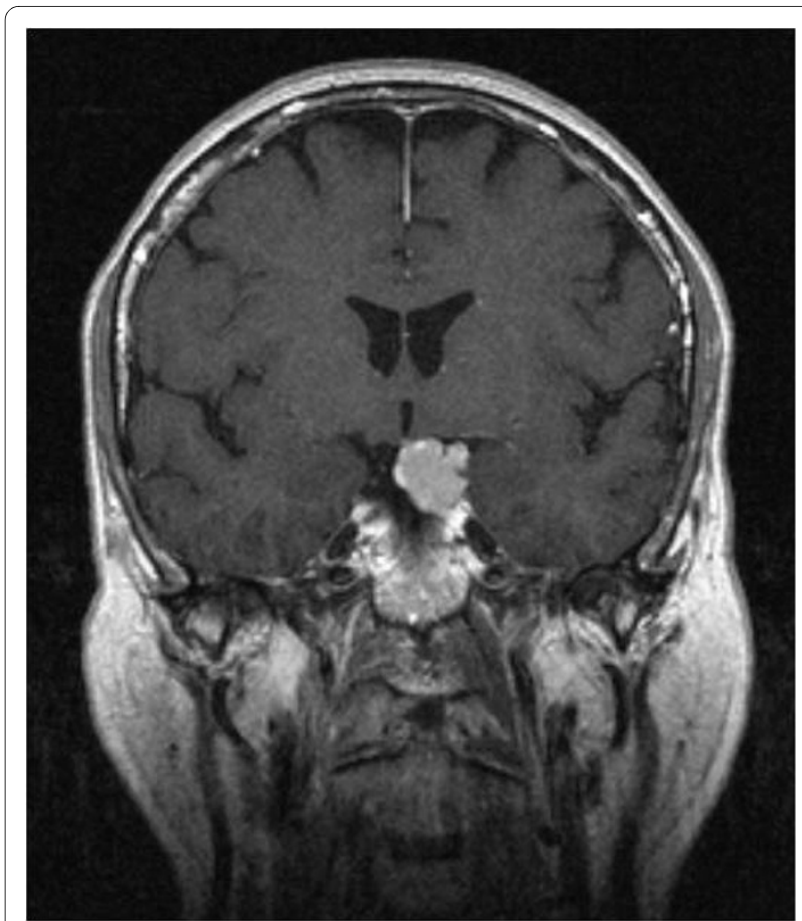

Figure 6 MRI, T1 weighted images after administration of gadolinium, coronal section, demonstrates the circumscribed skull base tumor.

\section{Case report 3}

66-year-old patient, presented with a history of six seizures, suffers from a known retrochiasmal lesion with a growth in the MRI examinations.

We addressed the tumor via the pterional approach from the right side (Figure 10). The chiasm is visible during the resection (Figure 11). We used a grasping forceps and the sucker to shrink the tumor in a piecemeal fashion. A small residue was left around the infundibular stalk (Figure 12).

\section{Outcome}

There were no neurological deficits and the healing of the wound was by first intention. In contrast the patient showed fluctuating vigilambulism with nausea, vertigo and electrolyte imbalance. The patient was prescribed a long-term hydrocortisone substitution and Desmopressin (Minirin) for a short period of time.

\section{Ad 2) frontolateral approach}

\section{Historical overview}

The frontolateral or unilateral subfrontal approach provides exposure of the anterior cranial base. It allows addressing olfactory groove meningiomas (OGMs) by a minimally invasive procedure and it is also one of the traditionally used approaches on OGMs $[9,10]$. Francesco Durante [11] marks the beginning of OGM extirpation. It 


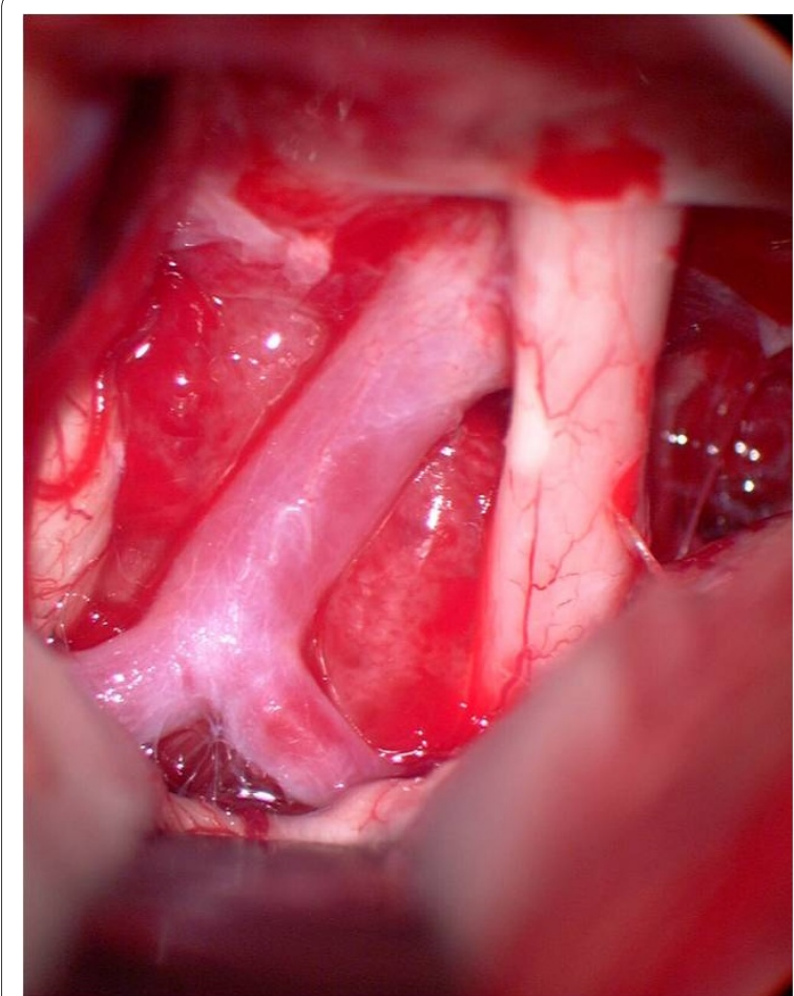

Figure $\mathbf{7}$ Intraoperative view, left pterional approach. The tumor bulges behind the internal carotid artery. In front of the tumor the left optic nerve can be seen. Behind the tumor the oculomotor nerve is demonstrated.

was not until Fedor Krause [12], who used the unilateral subfrontal approach the first time to expose the sellar region. In contrast to Krause's tremendous impact on anterior fossa approach, Durante removed an OGM in 1885 via a transpalatine approach through an extension into the nasal fossae.

\section{Surgical technique}

This approach allows different skin incisions, which depend on the patient's anatomy and physiognomy. The osteoplastic trepanation above the pterion and above the temporal muscle follows a curved skin incision or an eyebrow skin incision [13] (Figure 13, Figure 14). The trepanation of an approximately $3 \times 4-\mathrm{cm}$ frontolateral craniotomy allows the entry to the anterior fossa. It is essential to include radiological data of the patient in order to prepare a performance of a sophisticated approach such as the frontolateral approach. A common iatrogenic injury is the injury of superficial structures. The superciliary skin incision allows the surgeon to protect superficial structures like the frontal branches of the facial nerve and the superficial temporal artery. Perneczky led to the development of endoscopical approaches

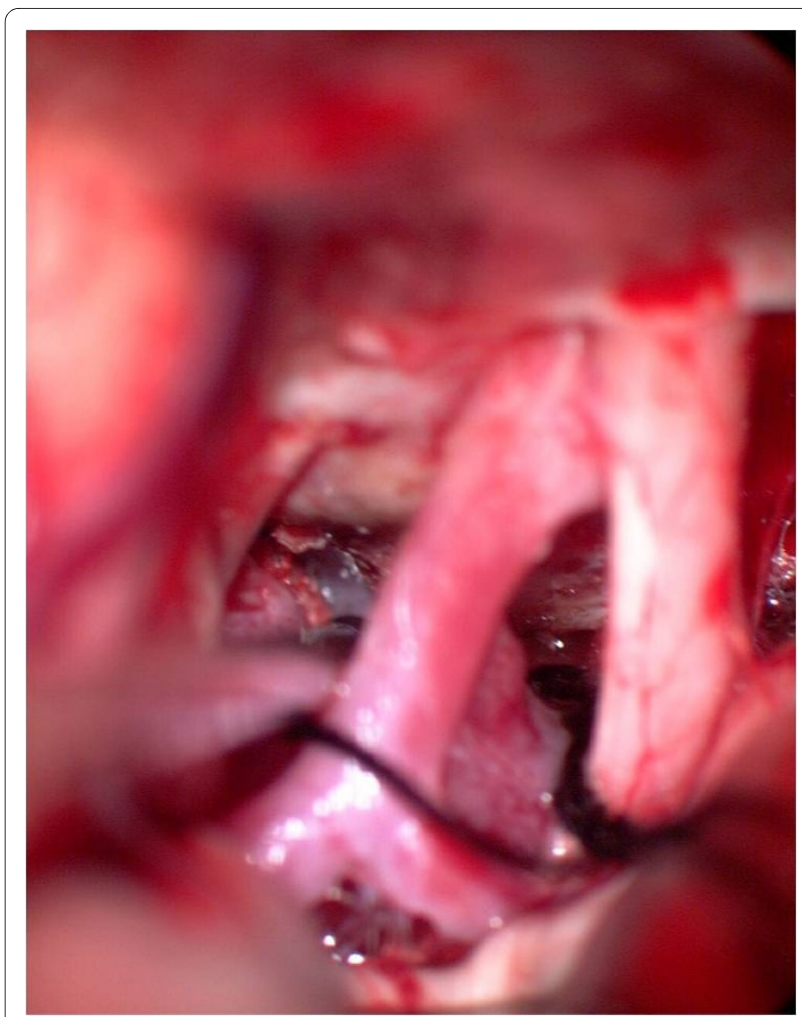

Figure 8 After tumor removal. The suction tip is located between internal carotid artery and oculomotor nerve.

using the supraorbital "key-hole" approach [14]. Via endoscopic techniques it is possible to provide relatively great exposure, while offering less brain retraction.

\section{Case report 4}

A 47-year-old patient with bitemporal hemianopsia and a 6-weeks history of progredient headache was presented. The patient manifested no further neurological deficits.

Neuropathological findings revealed parts of an epithlial cyst inflammatory cell infiltration in connective tissue stroma. The MRI showed a cystic lesion above the pituitary gland (Figure 15). We performed a frontolateral approach, in order to expose the Rathke's cleft cyst (Figure 16) and to remove it (Figure 17).

\section{Outcome}

The further course was without any complications and the wound healing was per primam.

Visual field defects were on the decrease. Furthermore, we couldn't recognize any hormonal failure.

\section{Ad3) transsphenoidal approach Historical overview}

The transsphenoidal route was first used by the Egyptians in order to remove the brain. The pioneering work of 


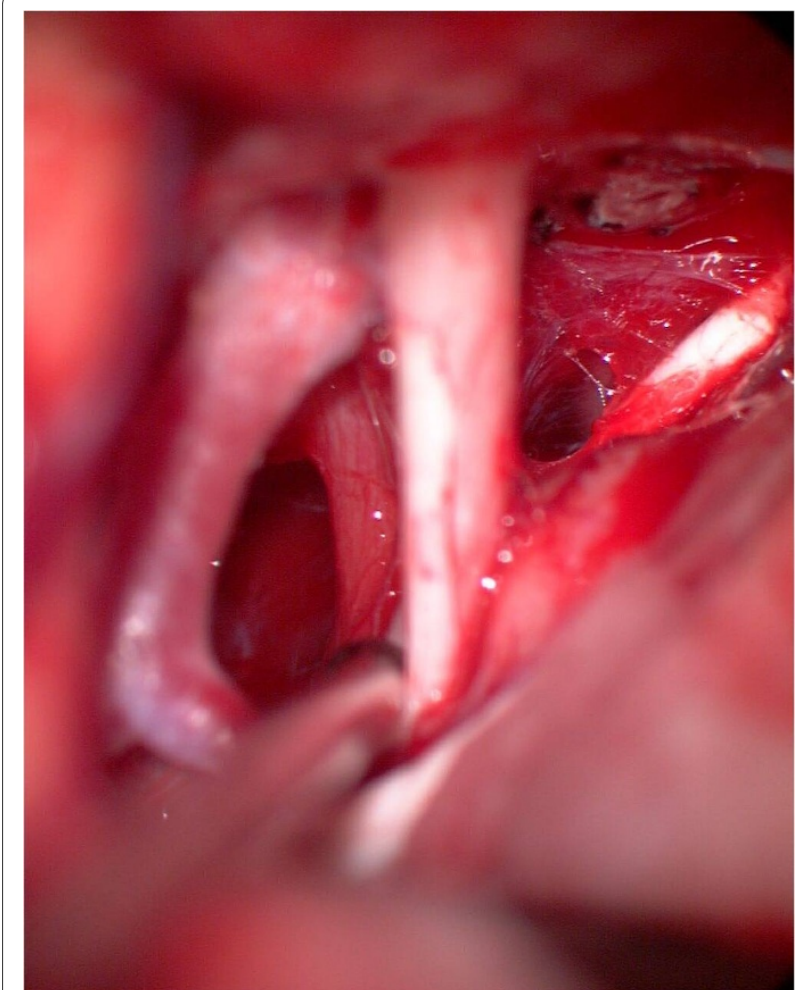

Figure 9 Image of the pituitary stalk. The pituitary stalk is demonstrated with the suction tip behind the chiasm.

Harvey Cushing [15] and Oskar Hirsch [16] led to one of the most efficient ways to operate in the sellar region. Cushing advocated the approach sublabially and Hirsch accessed the sellar region endonasally. Before Cushing and Hirsch led to the milestone in pituitary gland surgery, Sir Victor Horsley [17] was the first to operate on the pituitary gland. While the minimally invasive surgery

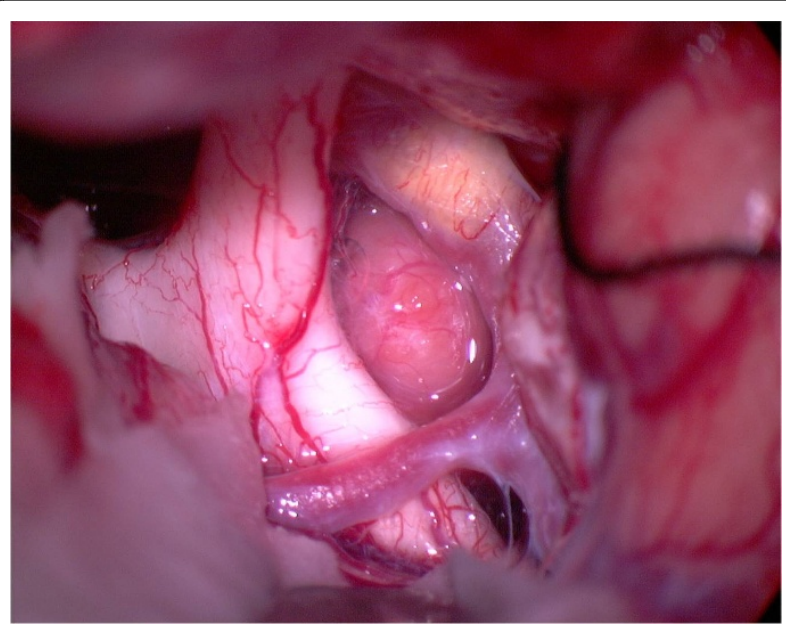

Figure 10 Pterional approach. Different steps during resection of a granular cell tumor of the pituitary stalk from the right side.

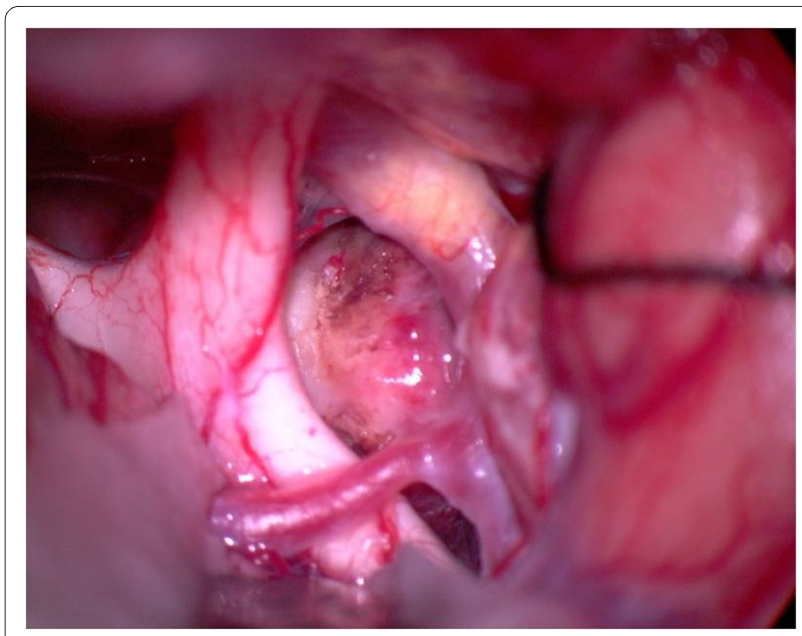

Figure 11 Beginning of the resection via the pterional approach. The chiasm is clearly visible.

trend is set in motion nowadays, the contemporary neurosurgeons would call Sir Horsley's approach too radical. His route required the retraction of the frontal lobe. In 1898 D. Giordano [18] developed the fundamental concepts to expose the pituitary gland via a transnasal-frontoethmoidal approach. But the contemporary standard route to the pituitary gland is carried out through the transsphenoidal approach.

\section{Surgical technique}

The classic technique begins with the patient in supine position. An x-ray machine is positioned laterally to control each step of intervention. In microsurgery the surgeon stands at the tip of the head whereas in pure endoscopic pituitary surgery the neurosurgeon stands at the shoulder of the patient. We would like to concentrate

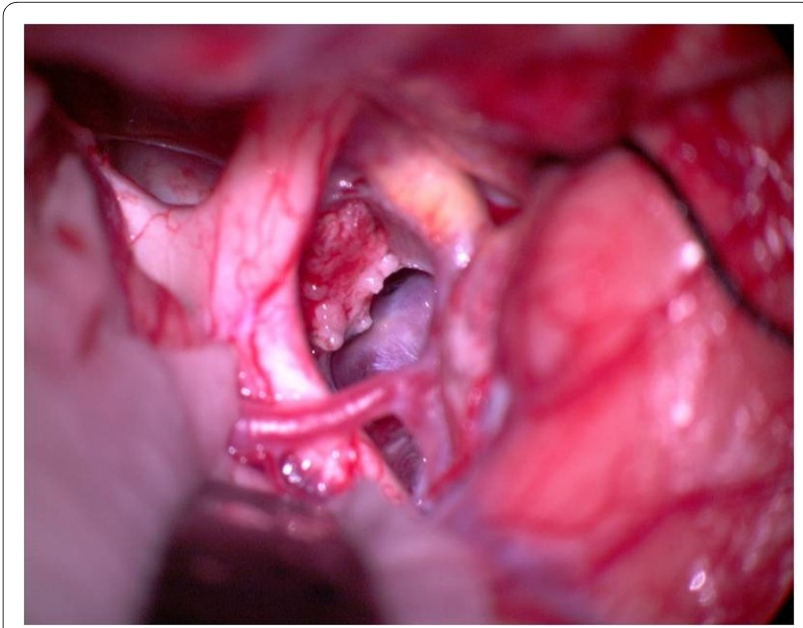

Figure 12 After the resection of the tumor via the pterional approach. Remnants of the tumor attached to the pituitary stalk are left behind. 


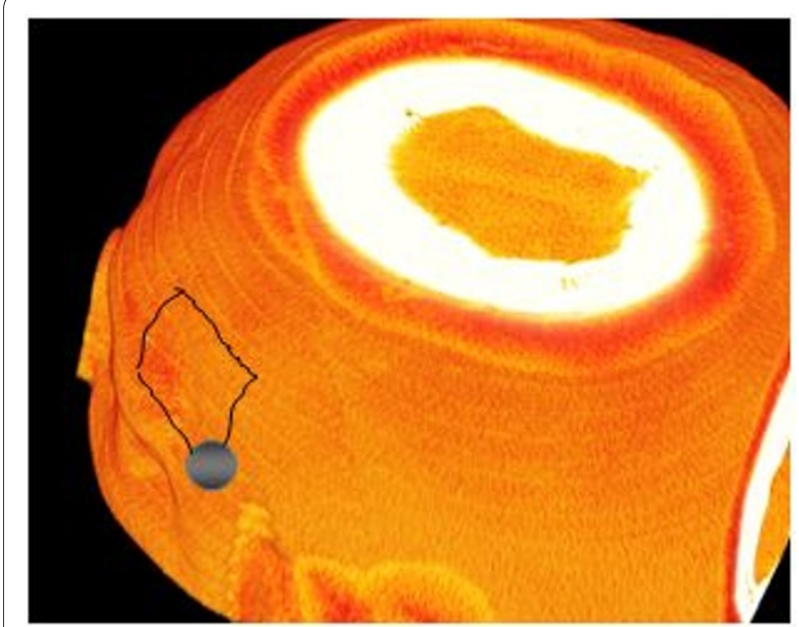

Figure 13 Computer animation of a left frontolateral approach from the lateral view. This trepanation can usually be done via one single burr hole.

on the microsurgical approach in our review article. After incising the septal mucosa (Figure 18) and revealing the anterior wall of the sphenoid sinus, the anterior wall of the sphenoid sinus will be removed with punch forceps (Figure 19, 20). We then excise the sinus mucosa. After opening the dura (Figure 21), the tumor must be indentified in order to extirpate it with a curette (Figure 22) by using lateral extensions. The transsphenoidal route is portrayed as the fundamental treatment of pituitary adenomas and other tumors in the sellar region $[19,20]$.

\section{Ad 4) suboccipital lateral approach}

\section{Historical overview}

The posterior cranial base can be explored through the lateral suboccipital route. Processes in the posterior fossa such as acoustic neurinoma surgery can be carried out

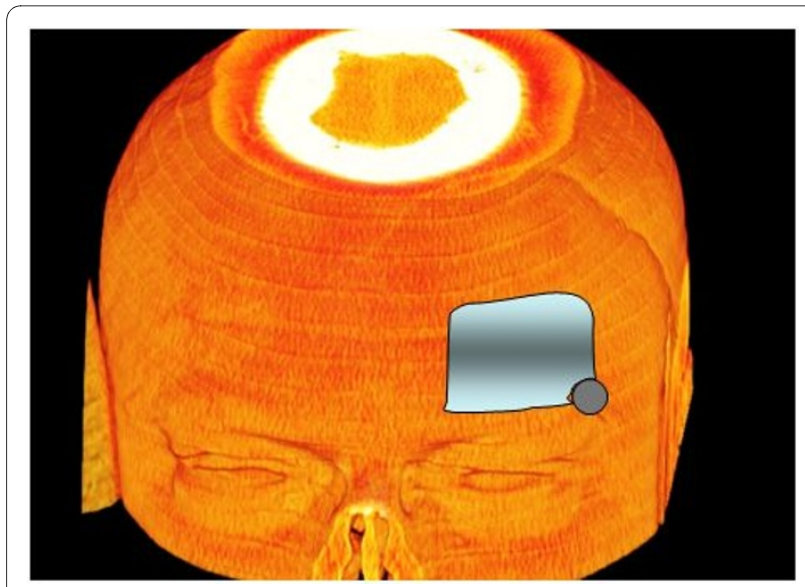

Figure 14 Computer animation of a left frontolateral approach from the frontal view. If the frontal sinus will be opened it has to be closed carefully with a galea flap.

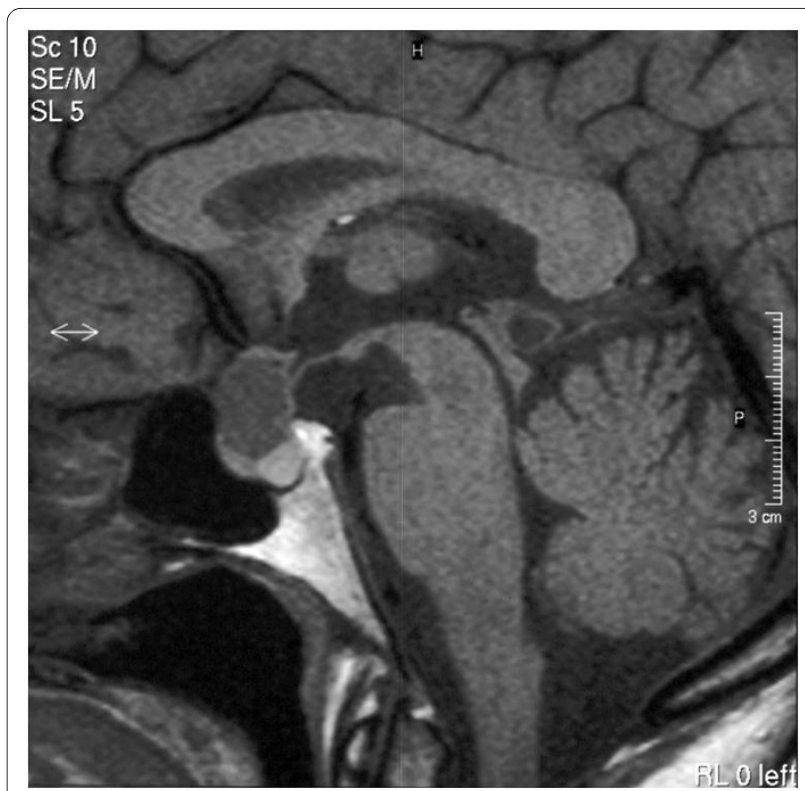

Figure 15 MRI, T1 weighted images, saggital section. A cystic lesion can be seen above the pituitary gland.

through the lateral suboccipital approach. The unilateral suboccipital approach was popularized by Woolsey (1903) and with great contributions by Krause (1905) $[21,22]$. After several refinements and modifications through different dedicated neurosurgeons (Fish [23], House [24,25] and Seiffert [26]), Dandy's [27] suboccipital approach (1917) with an ipsilateral suboccipital flap evolved to what we call retrosigmoid transmeatal approach now. Cushing (1917) [28] on the other hand described a bilateral suboccipital access and stated the unilateral suboccipital approach as disadvantageous. In modern neurosurgery Majid Samii $[29,30]$ is considered

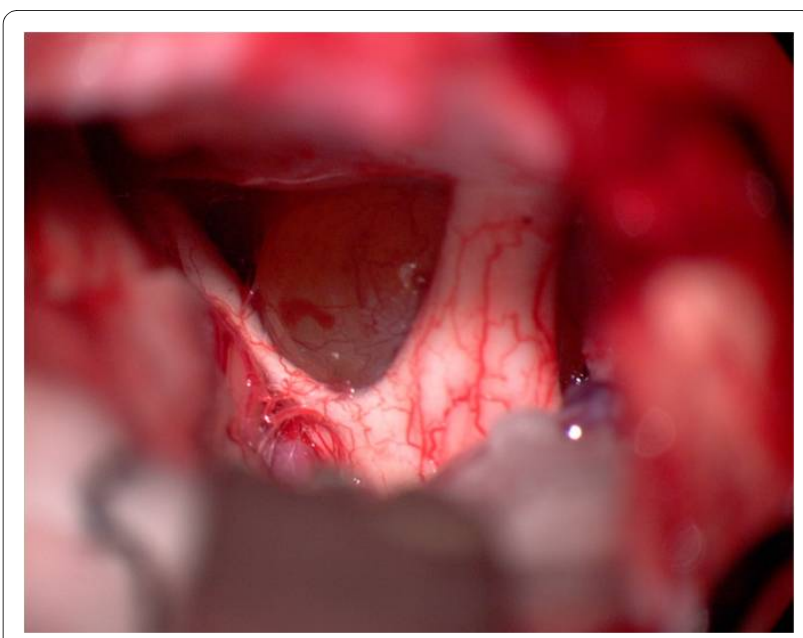

Figure 16 Intraoperative view from the right side. The cystic lesion (Rathke's cleft cyst) can be detected behind the optic nerves. 


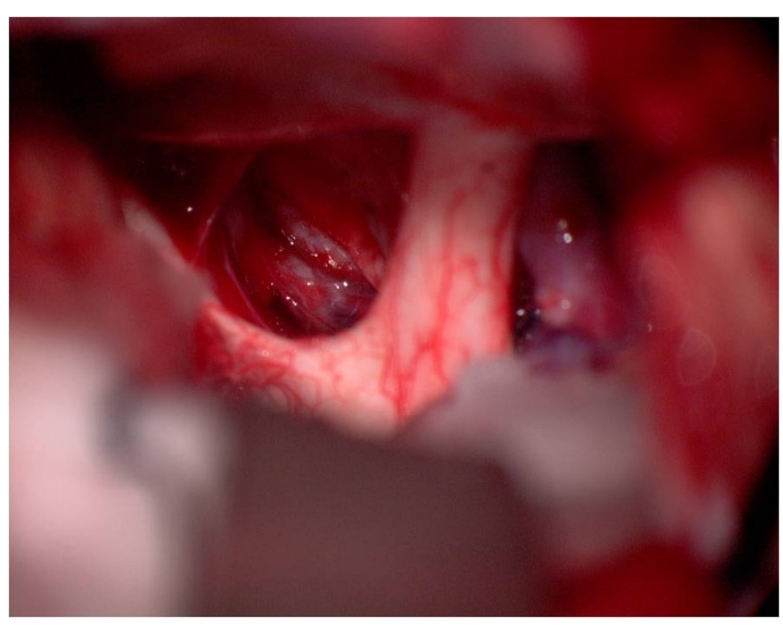

Figure 17 After resection

to be one of the leading experts in vestibular nerve schwannoma surgery.

\section{Surgical technique}

We normally use a semi-sitting position for the suboccipital lateral route (Figure 23). The operation can also be carried out with the patient in a lateral position at the surgeon's discretion. After local shaving of the hair behind the pinna and disinfection of the surgical field, a curved skin incision is made. This incision crosses a line running from the asterion to the protuberantia. The nuchal muscles are split with the monopolar knife. Either osteoclastic or osteoplastic bone resection can be done. Now the sigmoid sinus and parts of the transverse sinus are exposed with the drill.

Attention should be paid to the variable emissary veins, which lead to the sigmoid sinus. First the dura should be opened under microscopic magnification in

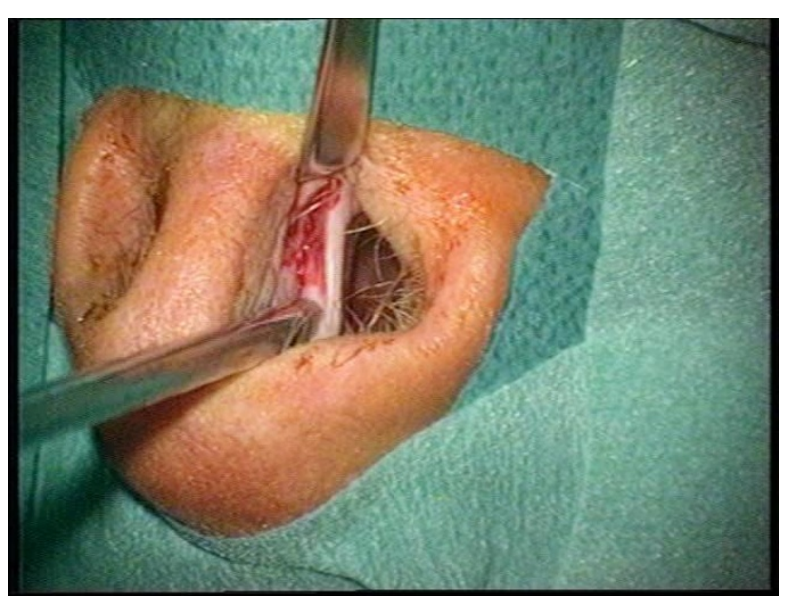

Figure 18 Incision inside the nasal ostium

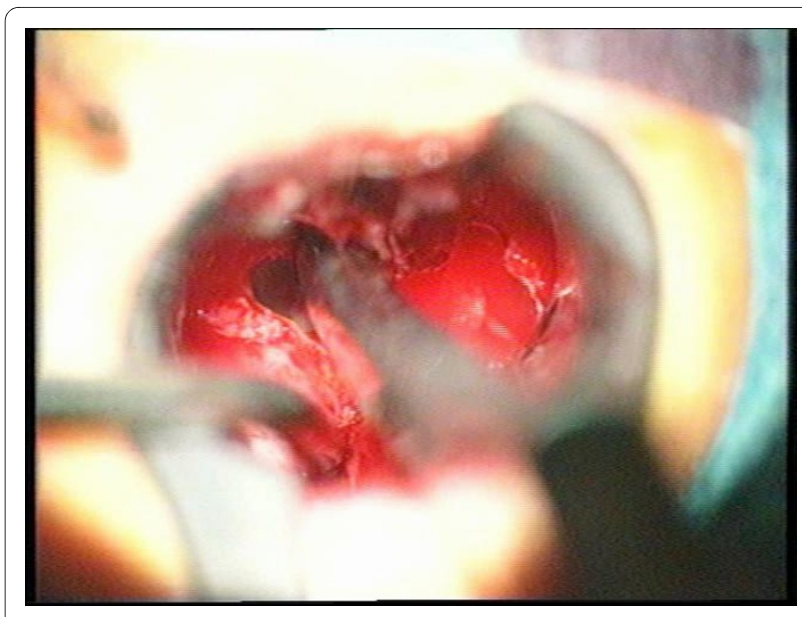

Figure 19 Partial resection of bony septum

a triangular shape in the region of the pars horizontalis to gain cerebrospinal fluid and in order to relax the cerebellum.

Then the dura has to be opened near the sinus via a curved skin incision that connects with the previous dural opening.

\section{Conclusion}

By applying the transsphenoidal, the unilateral subfrontal, pterional and lateral suboccipital approach, the surgeon can expose almost any skull base involvement. The diameters of exposure can be modified by combining different approaches. The introduction of microsurgical techniques in the $1960 \mathrm{~s}[31,32]$ is portrayed as a fundamental reason for the subsequently arising development in skull base surgery and the evolution of the approaches.

Complex pathologies at the skull base may need tailored approaches, which mainly have the base on one

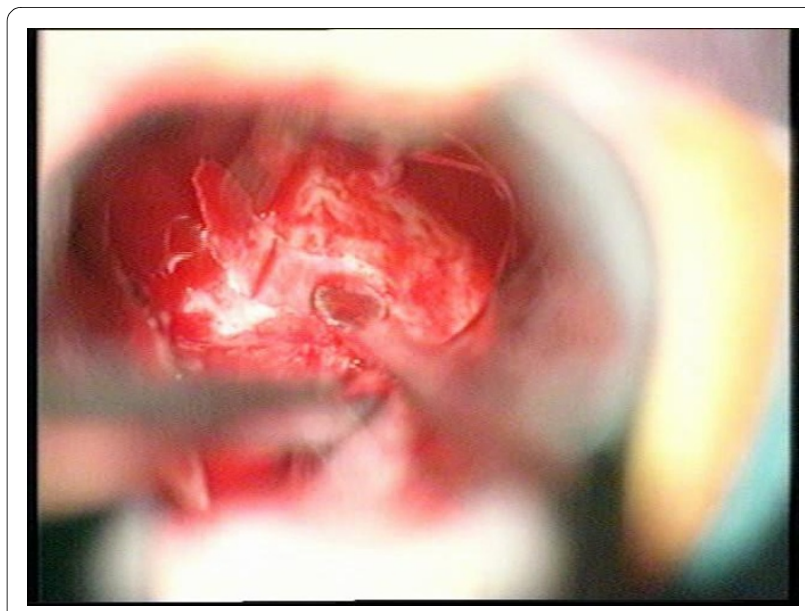

Figure 20 Opening of the sellar floor 


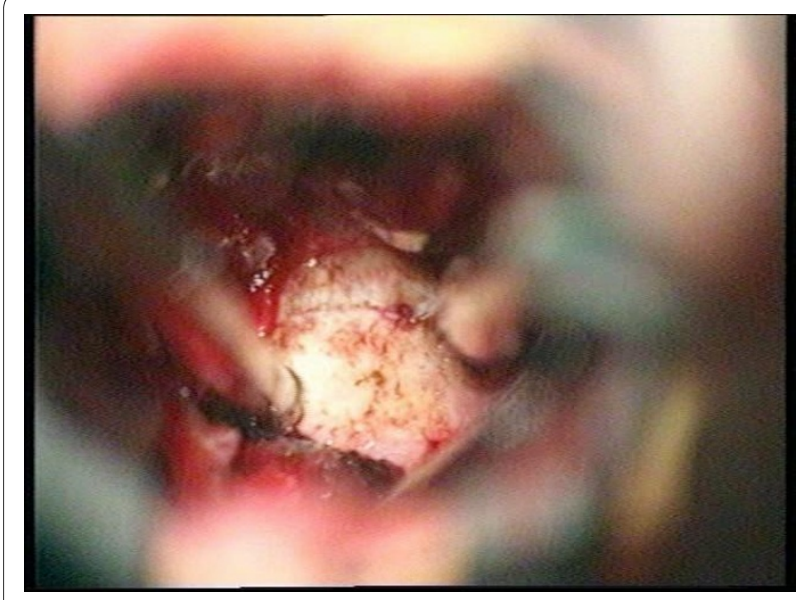

Figure 21 The dura is exposed and opened.

of the mentioned techniques. Extension of approaches can also be done in an interdisciplinary fashion with colleagues from other faculties like ENT or maxillofacical surgery, which is recommended by the author. While ENT can help accessing the skull base, e.g., in acoustic neuroma surgery [33] or by the help of an endoscope transnasally, maxillofacial surgery offers the wide spectrum of approaches through the oral cavity and maxilla.

\section{Consent}

A written informed consent was obtained from the patients for publication of the case reports and accompanying images. Copies of the written consents are available for review by the Editor-in-Chief of this journal.

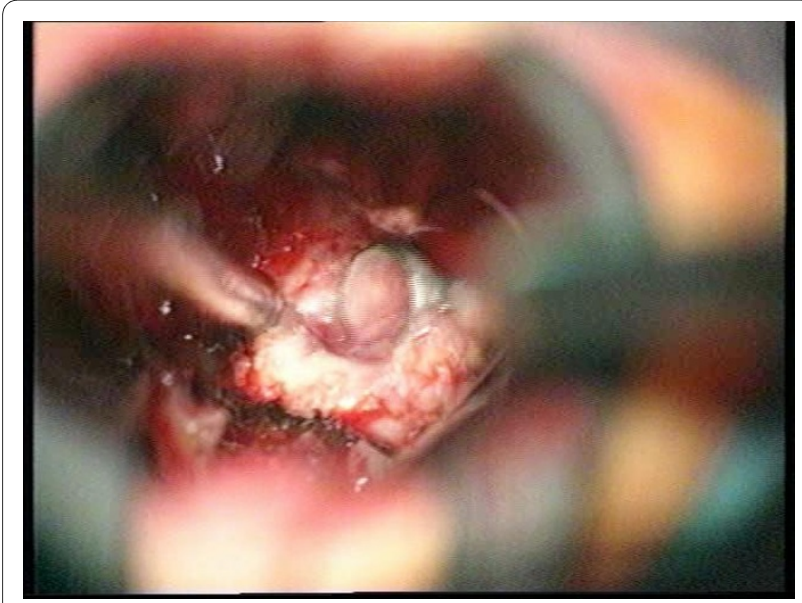

Figure 22 The tumor is resected with a curette.

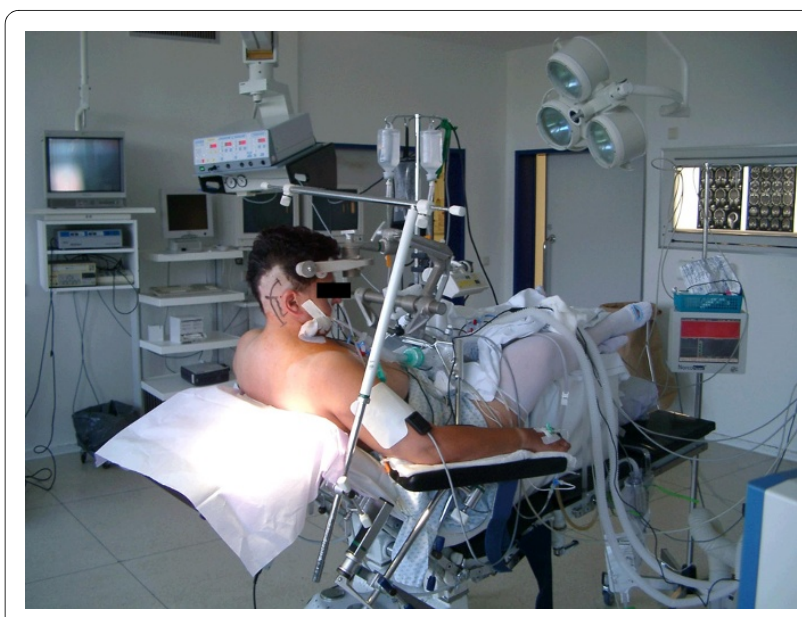

Figure 23 Patient in the semi-sitting position. The hair is shaved and the later skin incision is marked with a water resistant pencil.

\section{Competing interests}

The authors declare that they have no competing interests.

\section{Authors' contributions}

MS obtained clinical photos, coordinated, and drafted the manuscript. RP drafted the manuscript and participated in its coordination and design. JT, $C L$, $\mathrm{AH}$ and $\mathrm{KB}$ provided critical review of the manuscript for important intellectual content. All authors read and approved the final manuscript.

\section{Author Details}

'Department of Neurosurgery, Klinikum Duisburg, Academic Teaching Hospital of University Essen-Duisburg, Germany, ${ }^{2}$ Ruhr-University Bochum, Germany and ${ }^{3}$ Department of Neurosurgery, Knappschaftskrankenhaus, Germany

Received: 18 May 2010 Accepted: 5 July 2010

Published: 5 July 2010

\section{References}

1. Krayenbuhl HA, Yasargil MG, Flamm ES, Tew JM Jr: Microsurgical treatment of intracranial saccular aneurysms. J Neurosurg 1972, 37:678-86.

2. Yasargil MG, Antic J, Laciga R, Jain KK, Hodosh RM, Smith RD: Microsurgical pterional approach to aneurysms of the basilar bifurcation. Surg Neurol 1976, 6:83-91

3. Parkinson D: A surgical approach to the cavernous portion of the carotid artery: anatomical studies and case report. J Neurosurg 1965, 23:474-483

4. Parkinson D: Transcavernous repair of carotid cavernous fistula. Case report. J Neurosurg 1967, 26:420-424.

5. Dott NM: Intracranial aneurysms cerebral arterio-radiography and surgical treatment. Edinb Med J 1933, 40:219-34

6. Dandy WE: Intracranial arterial aneurysms. Ithaca, NY: Comstock Publishing; 1944.

7. Dandy WE: The surgical treatment of intracranial aneurysms of the internal carotid artery. Ann Surg 1941, 114:336-340.

8. Tönnis W: Traumatischer Aneurysma der linken Art. carotis int mit Embolie der linken Art. cerebri ant. und retinae. ZentrablfChir 1934, 61:844-848

9. Samii M, Ammirati M: Olfactory groove meningiomas. In Surgery of the Skull Base: Meningiomas Edited by: Samii M. Springer, Berlin; 1992:15-25.

10. Spektor S, Valarezo J, Fliss DM, Gil Z, Cohen J, Goldman J, Umansky F: Olfactory groove meningiomas from neurosurgical and ENT perspectives: approaches, techniques, and outcomes. Neurosurgery 57 : Operative Neurosurgery Supplement 4:268-280.

11. Durante F: Contribution to endocranial surgery. Lancet 1887, 2:654-655. 
12. Krause F: Chirurgie des Gehirns und Rückenmarks nach eigenen Erfahrungen. Volume 1. Berlin, Urban \& Schwarzenberg; 1908

13. Perneczky A, Muller-Forell W, van Lindert E: Keyhole Concept in Neurosurgery: With Endoscope-Assisted Microneurosurgery and Case Studies, New York: Thieme 1999.

14. Van Lindert E, Perneczky A, Fries G, Pierangeli E: The supraorbital keyhole approachto supratentorial aneurysms: concept and technique. Surg Neurol 1998, 49:481-490

15. Cushing H: Partial hypophysectomy for acromegaly: With remarks on the function of the hypophysis. Ann Surg 1909, 50:1002.

16. Hirsch O: Symptoms and treatment of pituitary tumors. Arch Otolaryngol 1952, 55:268.

17. Horsley V: On the technique of operations on the central nervous system. BMJ 1906, 2:411-423.

18. Guidetti B, Giuffrè R, Valente V: Italian contribution to the origin of neurosurgery. Surg Neurol 1983:335-46.

19. Honegger J, Buchfelder M, Fahlbusch R, Daubler B, Dorr HG: Transsphenoidal microsurgery for craniopharyngioma. Surg Neurol 1992, 37:189-196.

20. Honegger J, Fahlbusch R, Buchfelder M, Huk WJ, Thierauf P: The role of transsphenoidal microsurgery in the management of sellar and parasellar meningioma. Surg Neurol 1993, 39:18-24.

21. Krause F: Zur Freilegung der hinteren Felsenbeinfl228;che und des Kleinhirns. Beitr Klein Chir 1903, 37:728-764.

22. Krause F: Surgery of the Brain and Spinal Cord Volume II. Rebmann, New York; 1911:3-32.

23. Fisch U: Chirurgie im inneren Gehörgang und an benachbarten Strukturen. In Kopf und Hals-Chirurgie Volume 3. Edited by: Naumann HH. Thieme, Stuttgart, New York; 1976:457-543.

24. House WF: Transtemporal bone microsurgical removal of acoustic neuromas. Arch Otolaryngol 1964, 80:597-756.

25. House WF: Surgical exposure of the internal auditory canal and its contents through the middle cranial fossa. Laryngoscope 1961, 71:1363-1385

26. Seiffert A: Zur Operation der Akustikusneurinome. Z Hals-NaseOhrenheilkd 1937, 42:237-239.

27. Dandy WE: Results of removal of acoustic tumors by the unilateral approach. AMA Arch Surg 1941, 42:1026-1033.

28. Cushing H: Tumors of the Nervus Acusticus and the Syndrome of the Cerebellopontine Angle. Philadelphia: Saunders; 1917.

29. Samii M, Matthies C: Management of 1000 vestibular schwannomas (acoustic neuromas): surgical management and results with an emphasis on complications and how to avoid them. Neurosurgery 1997, 40:11-23.

30. Samii M, Draf W: Surgery of the internal auditory canal and cerebellopontine angle. In Surgery of the Skull Base. An Interdisciplinary Approach Edited by: Samii M, Draf W. Springer, Berlin Heidelberg; 1989:360-409

31. Yasargil MG, Fox JL, Ray MW: The operative approach to aneurysms of the anterior communicating artery. In Advances and Technical Standards in Neurosurgery Volume 2. Edited by: Krayenbühl H. Vienna, Springer Verlag; 1975:113-170.

32. Kurze T: Microtechniques in neurological surgery. Clin Neurosurg 1964 11:128-137.

33. Tonn J-C, Schlake H-P, Goldbrunner R, Milewski C, Helms J, Roosen K Acoustic neuroma surgery as an interdisciplinary approach: a neurosurgical series of 508 patients. J Neurol Neurosurg Psychiatry 2000, 69:161-166.

doi: $10.1186 / 1758-3284-2-16$

Cite this article as: Scholz et al., Skull base approaches in neurosurgery Head \& Neck Oncology 2010, 2:16

\section{Submit your next manuscript to BioMed Central} and take full advantage of:

- Convenient online submission

- Thorough peer review

- No space constraints or color figure charges

- Immediate publication on acceptance

- Inclusion in PubMed, CAS, Scopus and Google Scholar

- Research which is freely available for redistribution

Submit your manuscript at www.biomedcentral.com/submit
C Biomed Central 